\title{
Growth references for weight, height, and body mass index for Ecuadorian children and adolescents aged 5-19 years
}

\author{
Wilmer Tarupi, MSc. ${ }^{a *}$, Yvan Lepage, M.D. ${ }^{b}$, María L. Felix, M.D. ${ }^{a}$, Claude Monnier, M.D. ${ }^{b}$, \\ Roland Hauspie, M.D. ${ }^{(+)}$, Mathieu Roelants, M.D. ${ }^{d}$, Ricardo Hidalgo, M.D. ${ }^{a}$ \\ and Martine Vercauteren, M.D. ${ }^{b}$
}

\begin{abstract}
Introduction. The assessment of growth during childhood and adolescence is a critical component of health care at all levels, but it is also part of nutritional status diagnosis and the timely detection of related conditions. Ecuador lacks national growth references, soit has decided to adopt the international standards proposed by the World Health Organization. The objective of this study was to develop national references for weight, height, and body mass index for children and adolescents.
\end{abstract}

Methods. Ecuadorian schoolchildren and adolescents aged 5-19 years were studied between 1999 and 2012. The LMS method for cross-sectional data, which uses the Box-Cox transformation to normalize data distribution at each age, was applied to estimate the $3^{\text {rd }}, 10^{\text {th }}$, $25^{\text {th }}, 50^{\text {th }}, 75^{\text {th }}, 90^{\text {th }}$, and $97^{\text {th }}$ centiles for weight, height, and body mass index.

Results. A total of 5934 healthy subjects (2788 boys and 3146 girls) participated. Boys were heavier and taller than girls. In all cases, values increased with age. At 18 years old, the differences between sexes averaged $8 \mathrm{~kg}$ and $12.5 \mathrm{~cm}$.

Conclusion. The tables and curves obtained with this study are the first descriptive growth references for Ecuadorian children and adolescents aged 5-19 years. They are relevant for nutritional assessment. Their use at the primary level of care will aid in nutritional status diagnosis, which has traditionally been done based on the World Health Organization's international standards.

Key words: height, body mass index, adolescent, growth charts, Ecuador.

http: / / dx.doi.org/10.5546/ aap.2020.eng.117

To cite: Tarupi W, Lepage Y, Felix M L, Monnier C, et al. Growth references for weight, height, and body mass index for Ecuadorian children and adolescents aged 5-19 years. Arch Argent Pediatr. 2020;118(2):117-124.

(Ecuador). There are no conflicts of interest, and the manuscript was read and approved by all authors.

\section{Conflict of interest: \\ None.}

Received: 3-26-2019

Accepted: 10-8-2019

\section{INTRODUCTION}

Physical growth is one of the most useful instruments in the nutritional and health surveillance of children at the primary level of care. ${ }^{1}$ Although the growth pattern for children younger than 5 years, resulting from a multicenter study, provides a single international reference corresponding to the best description of physiological growth, ${ }^{2}$ this is not the case of growth references for children and adolescents aged 5-19 years ${ }^{3,4}$ based on the United States population. These curves are far from depicting the growth characteristics of childhood and adolescence, a period of life during which genetic, socioeconomic, and geographical influences are fully expressed. In this regard, several studies have demonstrated how growth and maturation patterns at this age vary greatly among and within populations. ${ }^{5-11}$

Growth assessment implies comparing the measures reached by an individual based on a standard. It has been argued that, if available, national growth standards may be more adequate to assess growth deviations and abnormal growth. ${ }^{10,12}$

Unlike other countries, like Argentina, ${ }^{13}$ Venezuela ${ }_{1}^{14}$ Colombia,${ }^{15}$ the United Kingdom, ${ }^{16}$ Japan, ${ }^{17}$ and Belgium, ${ }^{18}$ to date, Ecuador lacked national growth references for children and adolescents aged 5-19 years; therefore, at the time, the United States international growth standards were recommended for their use in this country., Since there is no global growth reference for the 5-19 age group, the availability of national references is considered 
critical. In this regard, the objective of this study was to develop national references for weight, height, and body mass index (BMI) for Ecuadorian children and adolescents aged 5-19 years.

\section{MATERIALS AND METHODS Sample}

This was a descriptive, cross-sectional study done in schoolchildren and adolescents aged 5 to 19 years. Data were collected across three periods: a) $1999,{ }_{1}^{19}$ b) $2007-2009,{ }^{20}$ and c) $2011-2012,{ }^{11}$ in the three continental regions of Ecuador, specifically, the cities of Quito and Tulcán (Andean region), Santa Elena (coastal region), and Tena (Amazon region). This way, the different Ecuadorian and regional ethnic groups (with their ecological differences) would be represented. Galápagos is the fourth region of Ecuador, but its population is very small. Both public and private schools in each city were randomly selected based on the school registry provided by the provincial education boards. Participants were recruited at the schools using a random sample stratified by age, sex, and place of residence (Table 1).

Weight and standing height were measured inside the classroom using the anthropometric technique proposed by the World Health Organization (WHO). ${ }^{21,22}$ Height was measured to the nearest $1.0 \mathrm{~mm}$ using a portable stadiometer (GPM Anthropological Instruments, Switzerland). Weight was measured at the nearest $0.1 \mathrm{~kg}$ using a manual scale (Health-o-Meter ${ }^{\circledR}$ HLT Scale), which was periodically calibrated. During the first two periods, measurements were obtained by the research team members and authors of this article, who were experienced in anthropometry. During the third period, there was room for the creation of a learning-teaching space with students from the school of medicine

TABLE 1. Distribution of individuals by sex and year of observation

\begin{tabular}{lccc}
\hline Place & Boys & Girls & Total \\
\hline Quito, 1999 & 459 & 629 & 1088 \\
Quito, 2007 & 730 & 520 & 1250 \\
Quito, 2009 & 344 & 381 & 695 \\
Quito, 2011 & 256 & 448 & 704 \\
Santa Elena, 2011 & 537 & 535 & 1072 \\
Tulcán, 2012 & 233 & 209 & 442 \\
Tena, 2012 & 229 & 454 & 683 \\
\hline Total & $\mathbf{2 7 8 8}$ & $\mathbf{3 1 4 6}$ & $\mathbf{5 9 3 4}$
\end{tabular}

of Universidad Tecnológica Equinoccial de Quito (UTE), who received previous training on how to make the measurements. The intra- and interobserver technical error of measurement (TEM) was $0.54 \%$ and $1.7 \%$, respectively. Measurements were obtained only once. All participants received the relevant feedback about their body measurements.

The date of birth was available for most participants in the official school records. Age and sociodemographic data were provided by parents and adolescents through a questionnaire. The central statistical analysis was done at the UTE, where data were digitalized and subjected to a comprehensive quality analysis. Suspicious values (due to rare measurement or typographical errors) were eliminated or corrected (as long as possible). The first step in data processing was to create dispersion plots and charts to exclude atypical values. Any observation above +3 standard deviations (SDs) and below -3 SDs of the sample median value was excluded before developing the growth references. As a result, 26 observations for males $(0.9 \%)$ and 49 observations for females $(1.5 \%)$ were excluded. Due to logistic limitations, the anthropometric data of these participants were not confirmed.

Children who were not of Ecuadorian nationality (18 observations), who had chronic conditions ( 8 observations) or who were receiving medications that may affect growth (6 observations) were excluded from the study.

\section{Data analysis}

The Least-Mean-Square algorithm (LMS) method $^{23}$ for cross-sectional data was used to estimate weight, height, and BMI percentiles. This allowed to adjust the asymmetry using a Box-Cox transformation (L), which normalized data distribution at each age, considering the median (M) and the coefficient of variation of distribution (S). Data adjustment allowed for $\mathrm{L}, \mathrm{M}$, and $\mathrm{S}$ values to change smoothly at the $x$-axis (in this case, age), so that they could be representative of the population with smoothed curves plotted based on the y-axis (weight, height, and BMI). At each age, weight, height, and BMI distribution was summarized into three coefficients: L, M, and S, where L accounted for the symmetry; M, for the median; and S, for the coefficient of variation for each age and sex. These parameters were estimated based on the penalized maximum likelihood method. ${ }^{24-26}$ These curves were then estimated using an iterative 
algorithm that included penalized cubic splines, where the smoothing level was determined by assigning the number of equivalent degrees of freedom (edf).

The adequate number of edf was selected as per Pan and Cole's description, ${ }^{27}$ based on deviation, ${ }^{23}$ Q-tests, ${ }^{28}$ and the worm plot. ${ }^{29}$ LMS curves smoothing and the acceleration and deceleration points of the mean curve were verified by inspecting their derivatives. The final models were validated by comparing the expected and observed proportions of observations in a set of percentile bands by age class, with a chi-square goodness-of-fit test (grid test). ${ }^{30}$ No significant deviations in expected frequencies were observed ( $p>0.1$ for all models). All curves were adjusted and validated with the package of functions in R. ${ }^{31}$

The $\mathrm{T}$ test was done to compare height, weight, and BMI in the different age groups of the three samples. Such detailed, comparative statistical analysis of the centiles in the three samples showed that, both graphically and statistically, there were no significant differences in the growth status of children in these three data groups: 1. Quito, 1999, 2. Quito, 2007, and Quito, 2009, and 3. Quito, 2011, Santa Elena, 2011, Tulcán, 2012, and Tena, 2012 ( $p \geq 0.05)$. Therefore, data from all sub-samples were combined to obtain an overall, larger sample that would allow to estimate the percentile lines more accurately.

\section{Ethical considerations}

The study was carried out in accordance with the guidelines established by the Declaration of Helsinki, and a written informed consent was obtained from all participating children's and adolescents' parents or legal guardians. The protocol was approved by the Ethics Committee of both associated institutions: the University Development Commission (Commission Universitaire pour le Développement, CUD) from Belgium and the UTE Review Board from Ecuador.

\section{RESULTS}

The study sample was made up of 5934 participants (3146 girls and 2788 boys) (Table 2). Boys were heavier and taller than girls. At 18 years old, the differences between sexes averaged $8 \mathrm{~kg}$ and $12.5 \mathrm{~cm}$.

The required level of smoothing was described in terms of edf, which were selected considering the penalized minimum deviation and maintaining the LMS order.

\section{Height (centimeters)}

Boys are taller than girls in all age ranges; the difference is more evident as of 13 years old. The reference percentiles for height-for-age in boys and girls are shown in Table 3, together with the $M$ and $S$ values, which provided the best fit to develop the growth references. The LMS models that provided the best fit were LMS $(\operatorname{edf}(\lambda)=0, \operatorname{edf}(\mu)=5, \operatorname{edf}(\sigma)=3)$ for boys and LMS $(\operatorname{edf}(\lambda)=3, \operatorname{edf}(\mu)=5, \operatorname{edf}(\sigma)=3)$ for girls. The curves for boys and girls were modeled without bias (edf $=0$, and L was set at 1 ).

\section{Weight (kilograms)}

Boys are heavier than girls in all age ranges; the difference is more evident as of 15 years old. The references for weight-for-age in boys and girls are shown in Table 4. The LMS models that provided the best fit to develop the weight references were LMS $(\operatorname{edf}(\lambda)=2, \operatorname{edf}(\mu)=5, \operatorname{edf}(\sigma)=3)$ for boys and LMS $(\operatorname{edf}(\lambda)=3, \operatorname{edf}(\mu)=5$, $\operatorname{edf}(\sigma)=3$ ) for girls. A positive asymmetry ( $\mathrm{L}$ was below 1) was observed at all ages and in both sexes, so the lower centiles were relatively closer to the median, whereas the upper extreme percentiles were relatively more distant from the median.

\section{Body mass index}

The references for BMI-for-age in boys and girls are shown in Table 5. The LMS models that provided the best fit to develop the BMI references were LMS $(\operatorname{edf}(\lambda)=3, \operatorname{edf}(\mu)=5, \operatorname{edf}(\sigma)=3)$ for

TABLE 2. Distribution of participants by age

\begin{tabular}{cccc}
\hline Age & Boys & Girls & Total \\
\hline 5 & 69 & 67 & 130 \\
6 & 163 & 187 & 350 \\
7 & 149 & 183 & 332 \\
8 & 156 & 279 & 435 \\
9 & 164 & 209 & 373 \\
10 & 213 & 268 & 481 \\
11 & 224 & 239 & 463 \\
12 & 342 & 323 & 665 \\
13 & 306 & 281 & 587 \\
14 & 286 & 286 & 572 \\
15 & 251 & 253 & 504 \\
16 & 188 & 230 & 418 \\
17 & 182 & 213 & 395 \\
18 & 63 & 88 & 151 \\
19 & 32 & 40 & 66 \\
\hline Total & 2788 & 3146 & 5934 \\
\hline
\end{tabular}


boys and $\operatorname{LMS}(\operatorname{edf}(\lambda)=3$, edf $(\mu)=5, \operatorname{edf}(\sigma)=3)$ for girls. Compared to weight, BMI showed a more positive asymmetry but a smaller coefficient of variation.

The information included in the tables was represented in curves using percentiles ${ }^{32}$ (Annexes 1, 2, 3, and 4). In all cases, values increased with age. The design of the reference curves was the same as that adopted in Norway, Luxembourg, and Algeria.

The reference curves for girls also show the distribution in age centiles at the time of menarche in the Ecuadorian population, based on the methodology developed by Lepage. ${ }^{33}$ This tool helps to assess the normality of the maturation rate in girls.

\section{DISCUSSION}

In this article, we present cross-sectional growth references for height, weight, and BMI for the Ecuadorian population based on a representative sample of children and adolescents aged 5-19 years. The sample was representative because it provided an adequate social and

TABLE 3. Height (cm) of children aged 5-19 years, Ecuador

\begin{tabular}{|c|c|c|c|c|c|c|c|c|c|}
\hline AGE in years & $\mathbf{L}$ & M (p50) & S & p3 & p10 & p25 & p75 & p90 & p97 \\
\hline \multicolumn{10}{|c|}{ BOYS } \\
\hline 5 & 1 & 105.8 & 0.047 & 96.4 & 99.4 & 102.4 & 109.2 & 112.3 & 115.3 \\
\hline 6 & 1 & 111.6 & 0.047 & 101.7 & 104.8 & 108 & 115.1 & 118.3 & 121.5 \\
\hline 7 & 1 & 117.2 & 0.047 & 106.8 & 110.1 & 113.5 & 121 & 124.4 & 127.7 \\
\hline 8 & 1 & 122.8 & 0.048 & 111.7 & 115.2 & 118.8 & 126.7 & 130.3 & 133.9 \\
\hline 9 & 1 & 127.8 & 0.049 & 115.9 & 119.7 & 123.5 & 132 & 135.9 & 139.7 \\
\hline 10 & 1 & 132.6 & 0.050 & 119.9 & 123.9 & 128 & 137.1 & 141.2 & 145.2 \\
\hline 11 & 1 & 137.5 & 0.051 & 124.2 & 128.5 & 132.8 & 142.3 & 146.6 & 150.8 \\
\hline 12 & 1 & 142.7 & 0.052 & 128.6 & 133.1 & 137.7 & 147.8 & 152.4 & 156.9 \\
\hline 13 & 1 & 148.3 & 0.054 & 133.2 & 138 & 142.9 & 153.7 & 158.6 & 163.4 \\
\hline 14 & 1 & 154.9 & 0.052 & 139.5 & 144.4 & 149.3 & 160.4 & 165.4 & 170.3 \\
\hline 15 & 1 & 160.5 & 0.048 & 145.9 & 150.5 & 155.2 & 165.7 & 170.4 & 175 \\
\hline 16 & 1 & 163.8 & 0.043 & 150.3 & 154.6 & 159 & 168.6 & 173 & 177.3 \\
\hline 17 & 1 & 165.4 & 0.041 & 152.7 & 156.7 & 160.8 & 170 & 174.1 & 178.2 \\
\hline 18 & 1 & 165.9 & 0.040 & 153.4 & 157.4 & 161.4 & 170.4 & 174.5 & 178.5 \\
\hline 19 & 1 & 166.0 & 0.039 & 153.6 & 157.5 & 161.6 & 170.5 & 174.5 & 178.5 \\
\hline \multicolumn{10}{|c|}{ GIRLS } \\
\hline 5 & 1 & 104.2 & 0.054 & 93.6 & 97 & 100.4 & 108.1 & 111.5 & 114.9 \\
\hline 6 & 1 & 110.4 & 0.050 & 99.9 & 103.3 & 106.7 & 114.2 & 117.6 & 120.9 \\
\hline 7 & 1 & 115.7 & 0.048 & 105.2 & 108.5 & 111.9 & 119.5 & 122.9 & 126.2 \\
\hline 8 & 1 & 120.9 & 0.047 & 110.1 & 113.5 & 117 & 124.8 & 128.3 & 131.7 \\
\hline 9 & 1 & 126.3 & 0.047 & 114.9 & 118.5 & 122.2 & 130.4 & 134 & 137.7 \\
\hline 10 & 1 & 132.2 & 0.048 & 120.1 & 123.9 & 127.9 & 136.5 & 140.4 & 144.3 \\
\hline 11 & 1 & 138.9 & 0.049 & 126.1 & 130.1 & 134.3 & 143.4 & 147.6 & 151.7 \\
\hline 12 & 1 & 144.5 & 0.048 & 131.3 & 135.5 & 139.8 & 149.2 & 153.4 & 157.6 \\
\hline 13 & 1 & 148.8 & 0.045 & 136.1 & 140.1 & 144.2 & 153.4 & 157.5 & 161.5 \\
\hline 14 & 1 & 151.4 & 0.042 & 139.2 & 143.1 & 147 & 155.8 & 159.7 & 163.6 \\
\hline 15 & 1 & 152.6 & 0.041 & 140.7 & 144.5 & 148.3 & 156.8 & 160.6 & 164.4 \\
\hline 16 & 1 & 153.0 & 0.040 & 141.2 & 145 & 148.8 & 157.2 & 161 & 164.7 \\
\hline 17 & 1 & 153.1 & 0.040 & 141.4 & 145.1 & 148.9 & 157.3 & 161 & 164.8 \\
\hline 18 & 1 & 153.2 & 0.040 & 141.5 & 145.2 & 149 & 157.4 & 161.1 & 164.9 \\
\hline 19 & 1 & 153.4 & 0.040 & 141.8 & 145.5 & 149.3 & 157.6 & 161.3 & 165 \\
\hline
\end{tabular}

cm: centimeters; L: Box-Cox power transformation; S: generalized coefficient of variation; M: 50th percentile; P3: 3rd percentile; P10: 10th percentile; P25: 25th percentile; P75: 75th percentile; P90: 90th percentile; P97: 97th percentile. 
geographical representation by means of a strict sampling design.

The data used to develop these curves were collected in different periods, and this may be considered a limitation of the study. However, a comparative statistical analysis of data from the three periods showed that there was no significant difference in the growth pattern of the children in these groups. In addition, the scientific literature provides a history of studies that combined population samples, as the one published by Tanner. ${ }^{34}$ For this reason, we decided to combine the data from the three periods mentioned above to obtain a larger sample that would allow to estimate percentile lines in a more accurate manner. Actually, most likely, the Ecuadorian population does not show a detectable secular trend in the period between the three surveys.

To assess the normality of a child's height/ weight, it is necessary to have reference data for percentiles P3 and P97 estimated as accurately as possible. Precisely, such extreme percentiles are the ones used to refer a child for a potential

TABLE 4. Weight $(\mathrm{kg})$ of children aged 5-19 years, Ecuador

\begin{tabular}{|c|c|c|c|c|c|c|c|c|c|}
\hline AGE in years & L & M (p50) & S & p3 & p10 & p25 & p75 & p90 & p97 \\
\hline \multicolumn{10}{|c|}{ BOYS } \\
\hline 5 & -1.09 & 17.6 & 0.179 & 13.2 & 14.3 & 15.7 & 20 & 22.9 & 26.8 \\
\hline 6 & -1.01 & 20.1 & 0.178 & 15.1 & 16.4 & 18 & 22.9 & 26.1 & 30.3 \\
\hline 7 & -0.93 & 22.8 & 0.178 & 17 & 18.5 & 20.3 & 25.9 & 29.5 & 34.1 \\
\hline 8 & -0.84 & 25.5 & 0.182 & 18.9 & 20.6 & 22.7 & 29 & 33.1 & 38.2 \\
\hline 9 & -0.74 & 28.3 & 0.190 & 20.6 & 22.6 & 25.1 & 32.4 & 37.1 & 42.9 \\
\hline 10 & -0.62 & 31.5 & 0.202 & 22.4 & 24.8 & 27.6 & 36.3 & 41.8 & 48.7 \\
\hline 11 & -0.49 & 35.1 & 0.215 & 24.3 & 27.1 & 30.5 & 40.8 & 47.2 & 55.2 \\
\hline 12 & -0.37 & 38.9 & 0.222 & 26.4 & 29.6 & 33.6 & 45.4 & 52.5 & 61.2 \\
\hline 13 & -0.29 & 43 & 0.218 & 29.2 & 32.9 & 37.3 & 50 & 57.6 & 66.6 \\
\hline 14 & -0.26 & 47.9 & 0.202 & 33.4 & 37.3 & 41.9 & 55.1 & 62.7 & 71.5 \\
\hline 15 & -0.27 & 52.6 & 0.183 & 37.8 & 41.9 & 46.6 & 59.7 & 67.1 & 75.6 \\
\hline 16 & -0.3 & 56.1 & 0.167 & 41.5 & 45.6 & 50.2 & 62.9 & 70 & 78 \\
\hline 17 & -0.32 & 58.4 & 0.152 & 44.4 & 48.3 & 52.8 & 64.8 & 71.4 & 78.8 \\
\hline 18 & -0.34 & 59.8 & 0.140 & 46.4 & 50.2 & 54.4 & 65.8 & 71.9 & 78.8 \\
\hline 19 & -0.35 & 60.6 & 0.132 & 47.8 & 51.4 & 55.5 & 66.4 & 72.2 & 78.7 \\
\hline \multicolumn{10}{|c|}{ GIRLS } \\
\hline 5 & -0.91 & 16.9 & 0.176 & 12.6 & 13.7 & 15.1 & 19.1 & 21.7 & 25 \\
\hline 6 & -0.87 & 19.3 & 0.172 & 14.5 & 15.8 & 17.3 & 21.8 & 24.7 & 28.2 \\
\hline 7 & -0.84 & 21.7 & 0.171 & 16.3 & 17.7 & 19.4 & 24.5 & 27.6 & 31.6 \\
\hline 8 & -0.83 & 24.3 & 0.177 & 18.1 & 19.7 & 21.7 & 27.6 & 31.3 & 35.9 \\
\hline 9 & -0.72 & 27.4 & 0.191 & 19.8 & 21.8 & 24.2 & 31.3 & 35.9 & 41.5 \\
\hline 10 & -0.45 & 31.1 & 0.208 & 21.7 & 24.1 & 27.1 & 35.9 & 41.3 & 47.8 \\
\hline 11 & -0.15 & 35.4 & 0.216 & 23.8 & 27 & 30.6 & 41 & 47 & 53.8 \\
\hline 12 & 0 & 39.7 & 0.213 & 26.6 & 30.2 & 34.4 & 45.9 & 52.2 & 59.4 \\
\hline 13 & -0.14 & 43.8 & 0.196 & 30.5 & 34.1 & 38.4 & 50 & 56.6 & 64 \\
\hline 14 & -0.37 & 47 & 0.174 & 34.5 & 37.9 & 41.9 & 53.1 & 59.4 & 66.8 \\
\hline 15 & -0.54 & 49.2 & 0.158 & 37.3 & 40.6 & 44.4 & 55 & 61.1 & 68.2 \\
\hline 16 & -0.66 & 50.6 & 0.147 & 39.2 & 42.3 & 45.9 & 56.1 & 62 & 68.8 \\
\hline 17 & -0.72 & 51.4 & 0.140 & 40.3 & 43.4 & 46.9 & 56.7 & 62.4 & 69 \\
\hline 18 & -0.76 & 51.8 & 0.137 & 40.9 & 43.9 & 47.4 & 57 & 62.6 & 69.1 \\
\hline 19 & -0.77 & 52 & 0.135 & 41.2 & 44.2 & 47.6 & 57.2 & 62.7 & 69.1 \\
\hline
\end{tabular}

kg: kilograms; L: Box-Cox power transformation; S: generalized coefficient of variation; M: 50th percentile; P3: 3rd percentile; P10: 10th percentile; P25: 25th percentile; P75: 75th percentile; P90: 90th percentile; P97: 97th percentile. 
additional medical examination. The data set on which references were based is large and representative enough of the study population to warrant the best estimation possible of the P3 and P97 percentile lines. In addition, the percentiles used in the current reference curves have been estimated based on the most advanced techniques, i.e., the LMS method developed by Tim Cole..$^{23}$

Growth references provide authorities with information about children's growth status and are critical to identify groups and individuals at risk for disease or requiring urgent care. ${ }^{35}$ Growth curves are used in the detection, surveillance, and follow-up of children's and adolescents' health, and are adequate to detect nutritional disorders. ${ }^{36}$ These references are a useful tool for the static and dynamic diagnosis of growth disorders, to track growth in surveillance systems, and analyze and report growth data and trends in different populations. ${ }^{37}$

Reference curves, developed for the Ecuadorian population, allow to detect children whose height/weight is above or below the

TABLE 5. Body mass index (BMI, $\left.\mathrm{kg} / \mathrm{m}^{2}\right)$ of children aged 5-19 years, Ecuador

\begin{tabular}{|c|c|c|c|c|c|c|c|c|c|}
\hline AGE in years & $\mathbf{L}$ & $M(p 50)$ & $S$ & p3 & p10 & p25 & p75 & p90 & p97 \\
\hline \multicolumn{10}{|c|}{ BOYS } \\
\hline 5 & -3.35 & 15.8 & 0.094 & 13.8 & 14.3 & 15 & 17 & 18.5 & 20.7 \\
\hline 6 & -2.74 & 16.2 & 0.107 & 13.8 & 14.4 & 15.2 & 17.6 & 19.2 & 21.7 \\
\hline 7 & -2.23 & 16.6 & 0.119 & 13.8 & 14.5 & 15.4 & 18.1 & 20 & 22.7 \\
\hline 8 & -1.82 & 17 & 0.132 & 13.8 & 14.6 & 15.6 & 18.7 & 20.8 & 23.6 \\
\hline 9 & -1.49 & 17.4 & 0.142 & 13.9 & 14.8 & 15.9 & 19.4 & 21.6 & 24.6 \\
\hline 10 & -1.23 & 18 & 0.141 & 14.1 & 15.1 & 16.3 & 20.1 & 22.5 & 25.6 \\
\hline 11 & -1.04 & 18.5 & 0.147 & 14.3 & 15.4 & 16.8 & 20.7 & 23.2 & 26.4 \\
\hline 12 & -0.91 & 19 & 0.148 & 14.6 & 15.8 & 17.2 & 21.3 & 23.8 & 27 \\
\hline 13 & -0.81 & 19.5 & 0.147 & 15 & 16.2 & 17.6 & 21.8 & 24.3 & 27.4 \\
\hline 14 & -0.73 & 20 & 0.142 & 15.4 & 16.7 & 18.1 & 22.3 & 24.7 & 27.6 \\
\hline 15 & -0.66 & 20.5 & 0.146 & 15.9 & 17.2 & 18.6 & 22.7 & 25 & 27.8 \\
\hline 16 & -0.58 & 20.9 & 0.139 & 16.4 & 17.6 & 19.1 & 23.1 & 25.3 & 27.8 \\
\hline 17 & -0.49 & 21.3 & 0.133 & 16.8 & 18.1 & 19.5 & 23.4 & 25.5 & 27.9 \\
\hline 18 & -0.4 & 21.7 & 0.127 & 17.2 & 18.5 & 19.9 & 23.7 & 25.7 & 27.9 \\
\hline 19 & -0.31 & 22 & 0.122 & 17.6 & 18.9 & 20.3 & 23.9 & 25.8 & 27.9 \\
\hline \multicolumn{10}{|c|}{ GIRLS } \\
\hline 5 & -1.88 & 15.6 & 0.116 & 12.9 & 13.6 & 14.5 & 16.9 & 18.6 & 20.7 \\
\hline 6 & -1.65 & 15.9 & 0.121 & 13.1 & 13.9 & 14.7 & 17.4 & 19.1 & 21.2 \\
\hline 7 & -1.46 & 16.3 & 0.128 & 13.2 & 14 & 15 & 17.8 & 19.6 & 21.9 \\
\hline 8 & -1.29 & 16.7 & 0.136 & 13.4 & 14.3 & 15.3 & 18.4 & 20.4 & 22.8 \\
\hline 9 & -1.12 & 17.2 & 0.144 & 13.6 & 14.5 & 15.7 & 19.1 & 21.2 & 23.8 \\
\hline 10 & -0.96 & 17.8 & 0.130 & 13.8 & 14.9 & 16.1 & 19.8 & 22 & 24.7 \\
\hline 11 & -0.83 & 18.4 & 0.133 & 14.2 & 15.3 & 16.6 & 20.5 & 22.8 & 25.6 \\
\hline 12 & -0.75 & 19 & 0.133 & 14.7 & 15.8 & 17.2 & 21.2 & 23.5 & 26.3 \\
\hline 13 & -0.69 & 19.8 & 0.150 & 15.3 & 16.5 & 17.9 & 22 & 24.3 & 27.1 \\
\hline 14 & -0.65 & 20.5 & 0.145 & 15.9 & 17.2 & 18.6 & 22.7 & 25 & 27.7 \\
\hline 15 & -0.62 & 21.1 & 0.139 & 16.5 & 17.8 & 19.2 & 23.2 & 25.5 & 28.1 \\
\hline 16 & -0.58 & 21.6 & 0.134 & 17 & 18.3 & 19.8 & 23.7 & 25.9 & 28.3 \\
\hline 17 & -0.54 & 21.9 & 0.129 & 17.5 & 18.7 & 20.2 & 24 & 26.1 & 28.5 \\
\hline 18 & -0.5 & 22.2 & 0.124 & 17.8 & 19.1 & 20.5 & 24.2 & 26.3 & 28.5 \\
\hline 19 & -0.47 & 22.5 & 0.120 & 18.1 & 19.4 & 20.8 & 24.4 & 26.4 & 28.6 \\
\hline
\end{tabular}

L: Box-Cox power transformation; S: generalized coefficient of variation; M: 50th percentile; P3: 3rd percentile; P10: 10th percentile; P25: 25th percentile; P75: 75th percentile; P90: 90th percentile; P97: 97th percentile 
"normal variation" (in general, above or below the P97 or P3, respectively). Such curves constitute a reliable tool only if they correctly represent the population, i.e., if data may be considered a representative sample of the population. For this reason, reference curves based on a study population always have a better performance than any other type of curves.

The reference curves published by the WHO are of great value as a common global reference that enables countries to establish their growth status. However, the WHO curves may hardly be representative of all other populations, especially during puberty and adolescence, when genetic, geographical, and socioeconomic differences are fully expressed. They are very useful for countries that lack their own growth data to develop local reference curves. ${ }^{12}$

It is worth noting some of the limitations of this study, such as the small number of data corresponding to the extreme ages ( 5 and 19 years), which did not prevent us from achieving a good fit. In fact, based on the statistical analysis, the models meet the assumption of normality after performing the power transformation.

Since at that time there was no global growth reference for this age group, these new curves should be used in the clinical practice in Ecuador as a complement of growth assessment, which, to date, has been done based exclusively on international tools.

\section{CONCLUSION}

The tables and curves obtained with this study are the first descriptive growth references for Ecuadorian children and adolescents aged 5-19 years; therefore, they may be used as a national, supplementary instrument for growth assessment and serve as the starting point for further research about this topic in Ecuador.

\section{Acknowledgments}

We would like to thank the more than 6000 children and adolescents, and their parents, for participating in the surveys, the schools, and the local authorities of the cities of Tulcán, Tena, Quito, and Santa Elena. Also, we want to thank the students of the school of medicine of the School of Health Sciences Eugenio Espejo, UTE, for their help with the collection of anthropometric measurements. Finally, we thank Professor Horacio Lejarraga for his contributions to the final manuscript.

\section{REFERENCES}

1. Lejarraga H. Consideraciones sobre el uso de tablas de crecimiento en Argentina. Arch Argent Pediatr. 2007; 105(6):545-51.

2. WHO Multicentre Growth Reference Study Group. WHO Child Growth Standards based on length/height, weight and age. Acta Paediatr. 2006; (Suppl 450):76-85.

3. Hamill PV, Drizd T, Johnson CL, Reed RB, et al. NCHS Growth Curves for children, Birth-18 years. United States. Vital Health Stat 11. 1977; (165):1-74.

4. De Onis M, Onvango AW, Borghi E, Sivam A, et al. Development of a WHO growth references for school-aged children and adolescents. Bull World Health Organ. 2007; 85(9):660-7.

5. Kulaga Z, Litwin M, Tkaczyk M, Rózdzynka A, et al. The height-, weight-, and BMI-for-age of Polish school-aged children and adolescents relative to international and local growth references. BMC Public Health. 2010; 10:109.

6. Rosario AS, Schienkiewitz A, Neuhauser H. German height references for children aged 0 to under 18 years compared to WHO and CDC growth charts. Ann Hum Biol. 2011; 38(2):121-30.

7. Sánchez González E, Carrascosa Lezcano A, Fernández García JM, FerrándezLongás A, et al. Estudios españoles de crecimiento: situación actual, utilidad y recomendaciones de uso. An Pediatr (Barc). 2011; 74(3):193.e1-16.

8. So HK, Nelson EA, Sung RY, Ng PC. Implications of using World Health Organization growth reference (2007) for identifying growth problems in Hong Kong children aged 6 to 18 years. Hong Kong Med J. 2011; 17(3):174-9.

9. AtalahS, Loaiza S, Taibo M. Estado nutricional en escolares chilenos según la referencia NCHS y OMS 2007. Nutr Hosp. 2012; 27(1):1-6.

10. Orden A, Apezteguía M. Weight and height centiles of Argentinian children and adolescents: a comparison with WHO and national growth references. Ann Hum Biol, 2016; 43(1):9-17.

11. Tarupi WA, Lepage $Y$, Hauspie R, Félix ML, et al. Estudio transversal del crecimiento infantil y de adolescentes en Ecuador. Rev Argent Antropol Biol. 2019; 21(2):e006.

12. Milani S, Buckler JM, Kelnar CHJ, Benso L, et al. The use of local reference growth charts for clinical use or a universal standard: a balanced appraisal. J Endocrinol Invest. 2012; 35(2):224-6.

13. Lejarraga H, Orfila G. Estándares de peso y estatura para niñas y niños argentinos desde el nacimiento hasta la madurez. Arch Argent Pediatr. 1987; 85(4):209-22.

14. López de Blanco M, Izaguirre de Espinoza I, Macias de Tomei C. Crecimiento y maduración física, bases para el diagnóstico y seguimiento clínico. Madrid:Panamericana; 2013.

15. Duran P, Merker A, Briceño G, Colón E, et al. Colombian References growth curves for height, weight, body mass index and head circumference. Acta Paediatr. 2016; 105(3):116-25.

16. Wright CM, Booth IW, Buckler JMH, Cameron N, et al. Growth reference charts for use in the United Kingdom. Arch Dis Child. 2002; 86(1):11-4.

17. Kagawa M, Tahara Y,MojiK, Nakao R, etal.Secular changes in growth among Japanese children over 100 years (19002000). Asia Pac J Clin Nutr. 2011; 20(2):180-9.

18. Roelants M, Hauspie R, Hoppenbrouwers K. References for growth and pubertal development from birth to 21 years in Flanders, Belgium. Ann Hum Biol. 2009; 36(6):680-94.

19. Monnier C, Vercauteren M, Susanne C. Estudio de crecimiento de la población escolar de Quito (Ecuador). Antropo. 2003; 5:9-20. 
20. Monnier C, Hauspie R, Cruz Albornoz J. Estudio del crecimiento y desarrollo de niños ecuatorianos residentes en Quito, según su origen social. Tsafiqui, 2011;2(2):129-42.

21. World Health Organization. Physical status: the use of and interpretation of anthropometry: Report of a WHO Expert Committee. Geneva: WHO; 1995.

22. World Health Organization. Multicentre Growth references Study Group. WHO child growth standards: length/ height-for-age, weight-for-age, weight-for-length, weightfor-height, and body mass index-for age: methods and development. Geneva: WHO; 2006.

23. Cole TJ, Green PJ. Smoothing reference centile curves: the LMS method and penalised likelihood. Stat Med. 1992; 11(10):1305-19.

24. Cole TJ. Using the LMS method to measure skewness in the NCHS and Dutch national height standards. Ann Hum Biol. 1989; 16(5):407-19.

25. Cole TJ. The LMS method for constructing normalized growth standards. Eur J Clin Nutr. 1990; 44(1):45-60.

26. Cole TJ. Constructing growth charts smoothed across time and space. In: Hauspie R, Lindgren G, Falkner F. Essays on Auxology presented to James Mourilyan Tanner. UK: Castlemead; 1995.Pages76-88.

27. Pan H, Cole TJ. A comparison of goodness of fit tests for age-related reference ranges. Stat Med. 2004; 23(11):1749-65.

28. Royston P, Wright EM. Goodness-of-fit statistics for agespecific reference intervals. Stat Med. 2000; 19(21):2943-62.

29. Van Buuren S, Fredriks M. Worm plot: A simple diagnostic device for modelling growth reference curves. Stat Med. 2001; 20(8):1259-77.

30. Healy M, Rasbash J, Yang M. Distribution-free estimation of age-related centiles. Ann Hum Biol. 1988; 15(1):17-22.

31. RCore Team. R:A language and environment for statistical computing. RFoundation forStatistical Computing, Vienna, Austria. 2018. [Accessed on: September $9^{\text {th }}$, 2019]. Available at: https: / / www.R-project.org/.

32. Lejarraga H. ¿Qué son los percentilos? Rev Hosp Niños (B Aires). 1974; 16(63):45-7.

33. Lepage Y, Tarupi W, Campbell J, Monnier C, et al. Edad de la menarquia en Ecuador. Antropo. 2014; 31:1-8.

34. Tanner J, Whitehouse R, Takaishi M. Standards from birth to maturity for height, weight, height velocity and weight velocity: British children, 1965. II. Arch Dis Child. 1966; 41(220):613-35.

35. De Onis M, Garza C, Victoria CG, Onyango AW, et al. The WHO Multicentre Growth References Study: Planning, study design, and methodology. Food Nutr Bull. 2004; 25(1 Suppl.):S15-26.

36. Fayter D, Nixon J, Hartley S, Rithalia A, et al. Effectiveness and cost-effectiveness of height-screening programmes during the primary school years: a systematic review. Arch Dis Child. 2008; 93(4):278-84.

37. DeOnis M, Garza C, Victoria CG, Bhan MK, etal. The WHO Multicentre Growth Reference Study: Rationale, planning, and implementation. Food Nutr Bull. 2004; 25(Suppl 1):S389. 
ANNEX 1. Ecuador, height- and weight-for-age, 5-19 years old. GIRLS

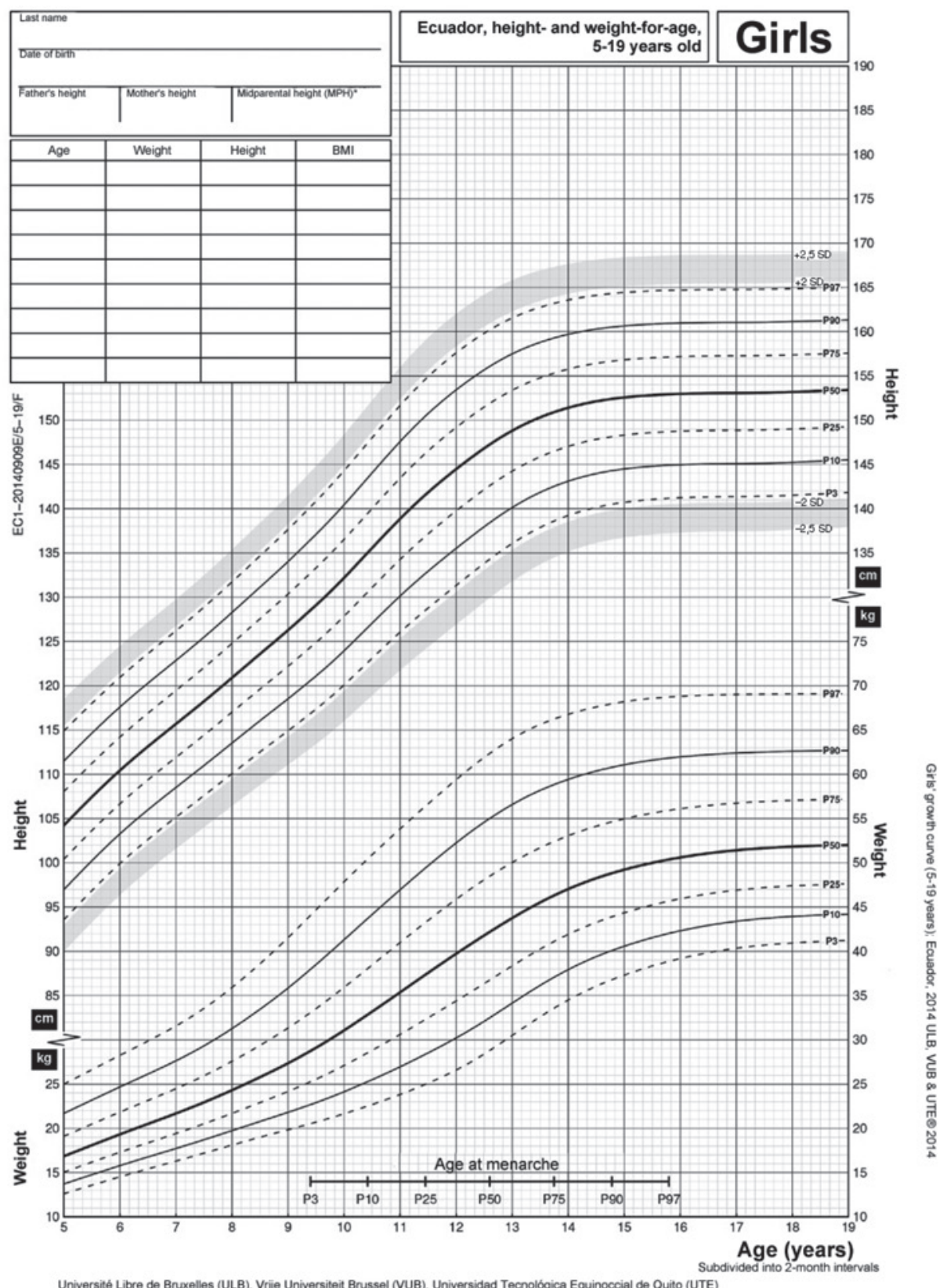

Université Libre de Bruxelles (ULB), Vrije Universitent Brussel (VUB), Universidad Tecnológica Equinoccial de Quito (UTE)

* Midparental height $(\mathrm{MPH})=($ father's height + mother's height -13$) / 2$; genetic range $=\mathrm{MPH} \pm 9 \mathrm{~cm}$. 


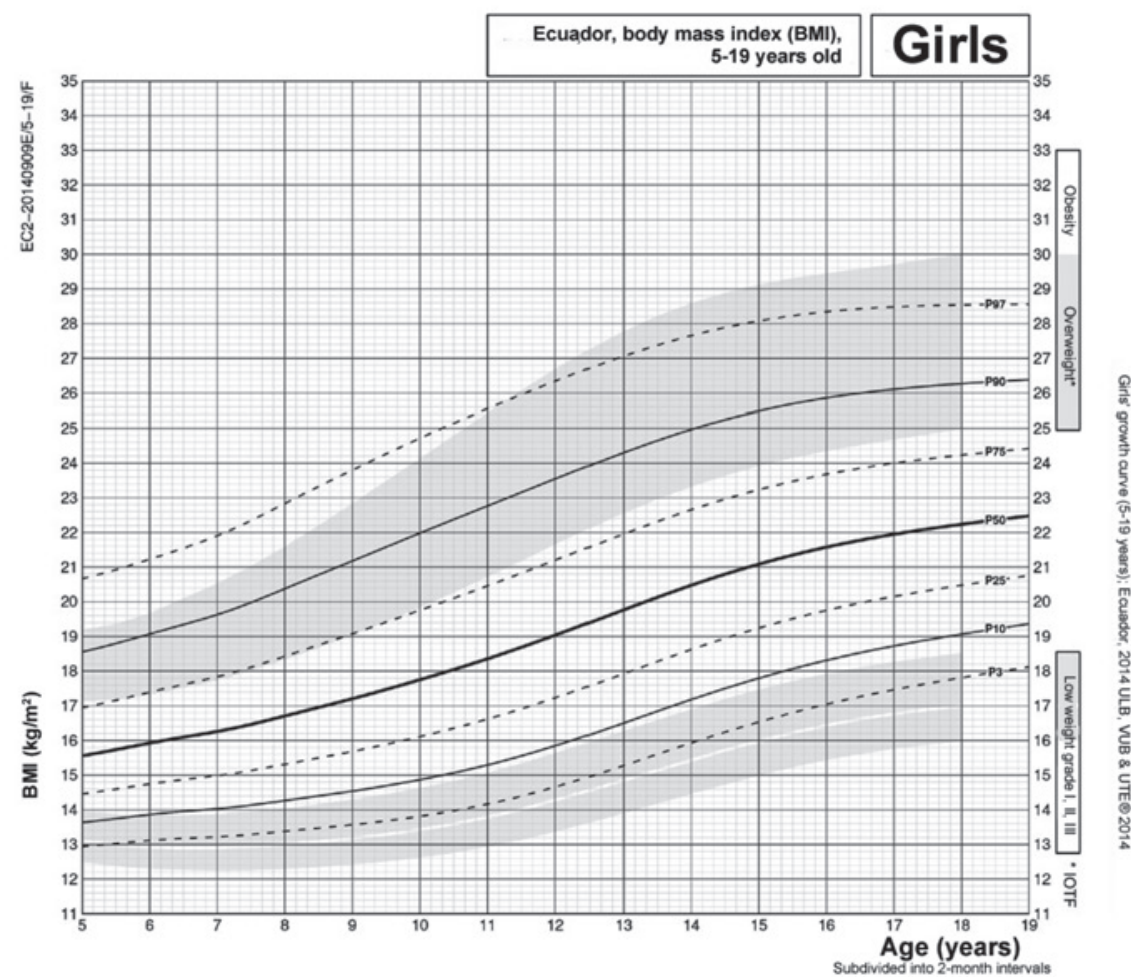

Height and weight standards ${ }^{(1)}$

C. Monnier, M. Roelants, W. Tarupi, Y. Lepage, R. Hauspie, J. Campbell, M.L. Félix, R. Hidalgo, and M. Vercauteren. The attached curves outline the height and weight growth in a group of more than 6000 Ecuadorian children and adolescents aged 5-19 years. Biometric, cross-sectional surveys were administered in Quito $(1999,2007,2009$, and 2011), Santa Elena (2011), Tulcán (2012), and Tena (2012) to students from public and private schools. ${ }^{(2)}$ Measured children came from different socioeconomic groups. Their parents' level of education and occupation reflect the diversity of Ecuadorian populations.

Chart interpretation: The curves show a measurement distribution in a group of children and allow to see the position of an individual within such group. Above the 50th percentile, which corresponds to the median, you can locate $50 \%$ of the group below and $50 \%$ of the group above. For example, the 10 th percentile represents, at each age, the value below which $10 \%$ of the population is located. Individuals outside the 2.5 th and 97.5 th percentiles are more than 2 standard deviations away from the median. It is recommended to control these children because they are at risk for developing a disease, as well as those whose growth curve is deviated before puberty.

Measurement technique: Weight. The child is weighted wearing light underwear and with no shoes on. Height. The child has to be standing upright but not rigidly, with the back against the stadiometer, the heels together, and the arms and hands hanging on the side of the body. The neck should not be bent forward and the child has to be looking straight ahead. The mobile piece of the stadiometer should be lowered towards the vertex (peak of the head), without pressing down. BMI (body mass index). Mass or weight (in kilograms) divided by the square of the height (in meters), kilograms/meters. (2)

(1) This project was conducted with the help of: Universidad Libre de Bruxelles (ULB), Vrije Universiteit Brussel (VUB) and Universidad Tecnológica Equinoccial (UTE Quito), and a CUD program.

(2) Data were collected by: C. Monnier, Y. Lepage, G. Pierard, A. Lepage, C. Reynaerts, J. Cruz-Albornoz (logistics), R. Buitron, W. Tarupi, J. Campbell; and fifth and sixth semester students for the 2011-2012 academic year of the school of medicine of the School of Health Sciences Eugenio Espejo. 
ANNEx 3. Ecuador, height- and weight-for-age, 5-19 years old. BOYS

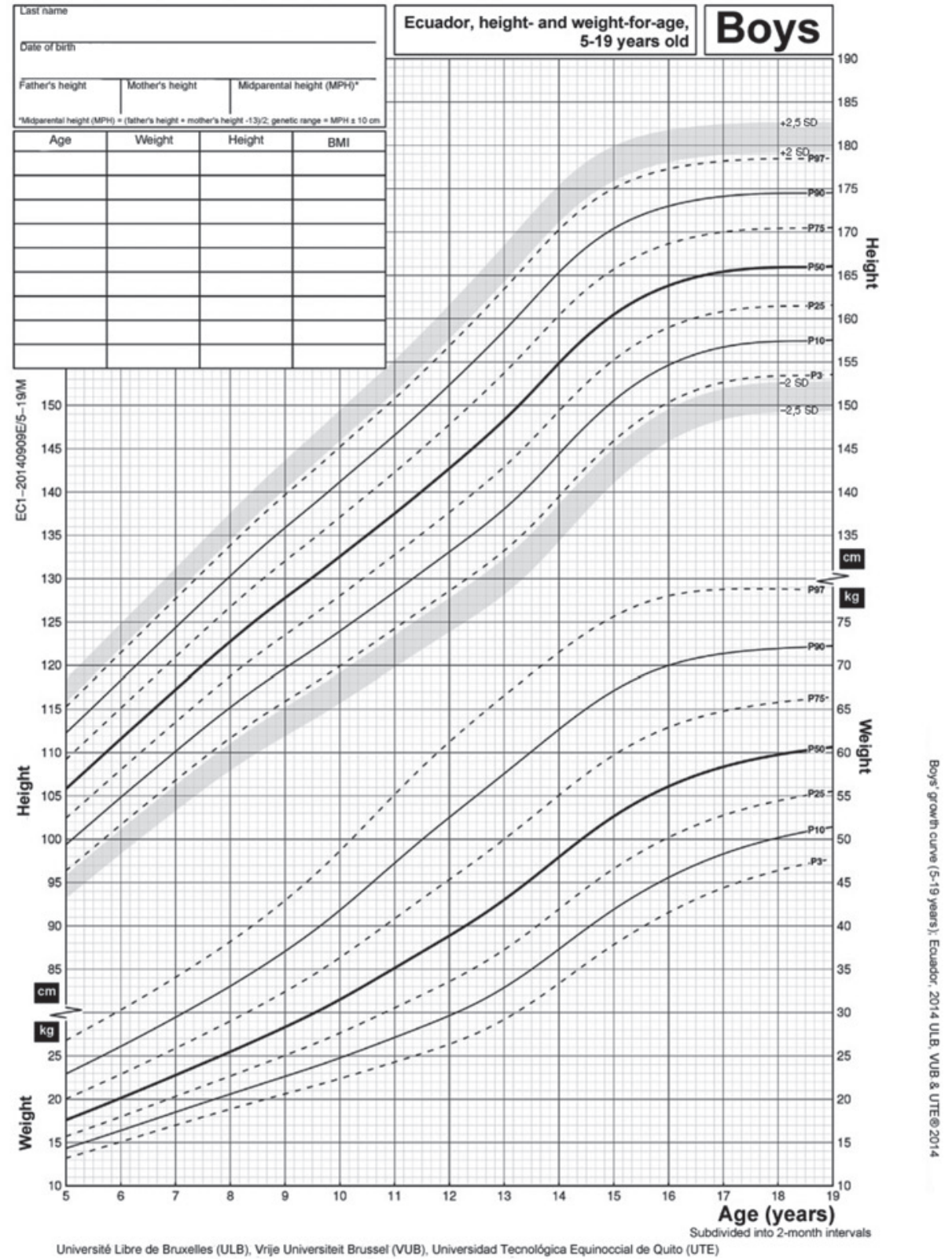

*Midparental height $(\mathrm{MPH})=($ father's height + mother's height -13$) / 2$; genetic range $=\mathrm{MPH} \pm 10 \mathrm{~cm}$. 
ANNEx 4. Ecuador, body mass index, 5-19 years old. BOYS

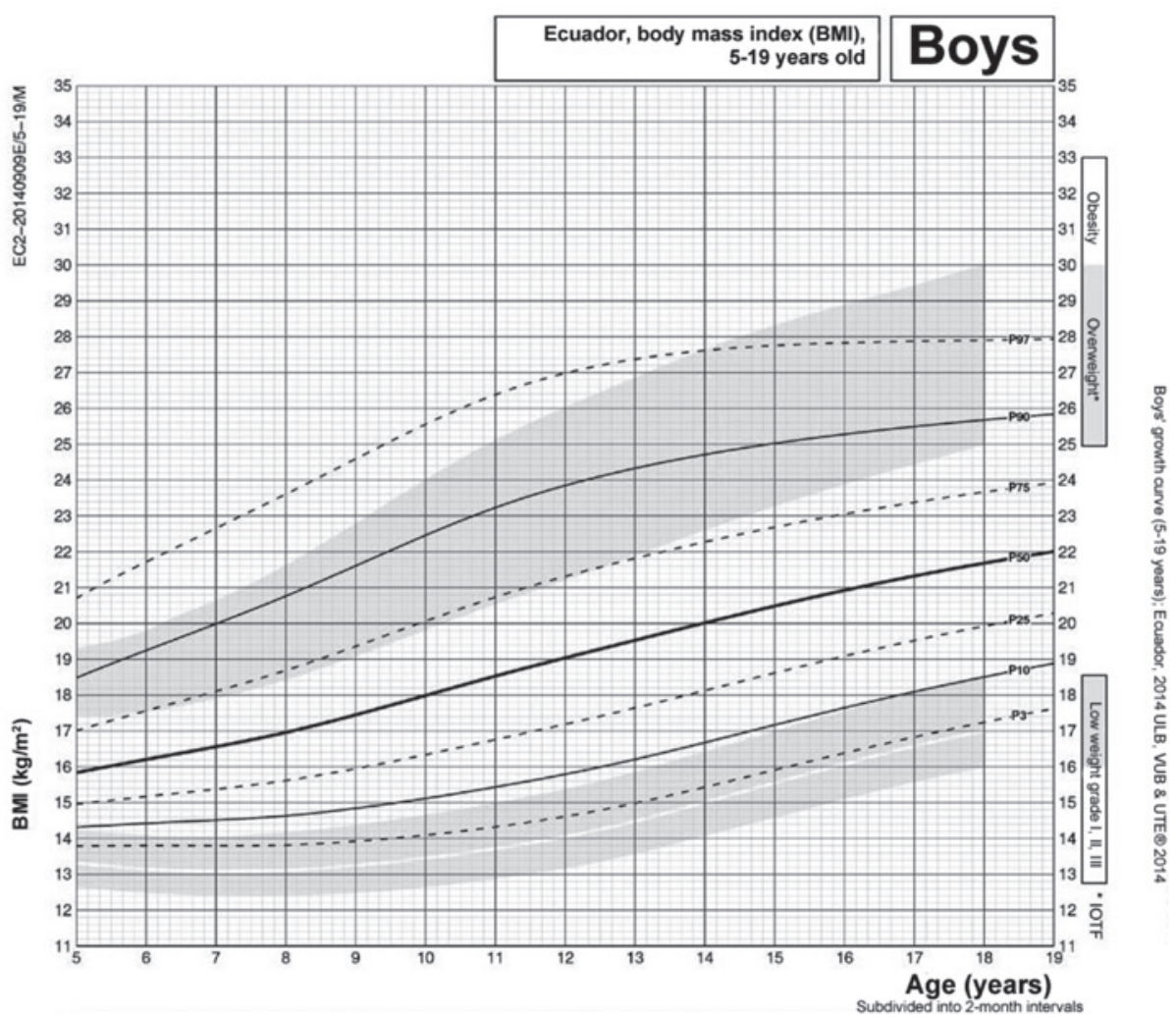

\section{Height and weight standards ${ }^{(1)}$}

C. Monnier, M. Roelants, W. Tarupi, Y. Lepage, R. Hauspie, J. Campbell, M.L. Félix, R. Hidalgo, and M. Vercauteren. The attached curves outline the height and weight growth in a group of more than 6000 Ecuadorian children and adolescents aged 5-19 years. Biometric, cross-sectional surveys were administered in Quito $(1999,2007,2009$, and 2011), Santa Elena (2011), Tulcán (2012), and Tena (2012) to students from public and private schools. ${ }^{(2)}$ Measured children came from different socioeconomic groups. Their parents' level of education and occupation reflect the diversity of Ecuadorian populations.

Chart interpretation: The curves show a measurement distribution in a group of children and allow to see the position of an individual within such group. Above the 50 th percentile, which corresponds to the median, you can locate $50 \%$ of the group below and $50 \%$ of the group above. For example, the 10 th percentile represents, at each age, the value below which $10 \%$ of the population is located. Individuals outside the 2.5 th and 97.5 th percentiles are more than 2 standard deviations away from the median. It is recommended to control these children because they are at risk for developing a disease, as well as those whose growth curve is deviated before puberty.

Measurement technique: Weight. The child is weighted wearing light underwear and with no shoes on. Height. The child has to be standing upright but not rigidly, with the back against the stadiometer, the heels together, and the arms and hands hanging on the side of the body. The neck should not be bent forward and the child has to be looking straight ahead. The mobile piece of the stadiometer should be lowered towards the vertex (peak of the head), without pressing down. BMI (body mass index). Mass or weight (in kilograms) divided by the square of the height (in meters), kilograms/meters. (2)

(1) This project was conducted with the help of: Universidad Libre de Bruxelles (ULB), Vrije Universiteit Brussel (VUB) and Universidad Tecnológica Equinoccial (UTE Quito), and a CUD program.

(2) Data were collected by: C. Monnier, Y. Lepage, G. Pierard, A. Lepage, C. Reynaerts, J. Cruz-Albornoz (logistics), R. Buitron, W. Tarupi, J. Campbell; and fifth and sixth semester students for the 2011-2012 academic year of the school of medicine of the School of Health Sciences Eugenio Espejo.

Université Libre de Bruxelles (ULB), Vrije Universiteit Brussel (VUB), Universidad Tecnológica Equinoccial de Quito (UTE) 